\title{
The role of oxytocin in cardiovascular regulation
}

\author{
J. Gutkowska ${ }^{1}$, M. Jankowski ${ }^{1}$ and J. Antunes-Rodrigues ${ }^{2}$ \\ ${ }^{1}$ Laboratory of Cardiovascular Biochemistry, Department of Medicine, Faculty of Medicine, University of Montreal, \\ CHUM Research Centre, Montreal, Quebec, Canada \\ ${ }^{2}$ Departamento de Fisiologia, Faculdade de Medicina de Ribeirão Preto, Universidade de São Paulo, Ribeirão Preto, SP, Brasil
}

\begin{abstract}
Studies of body volume expansion have indicated that lesions of the anteroventral third ventricle and median eminence block the release of atrial natriuretic peptide (ANP) into the circulation. Detailed analysis of the lesions showed that activation of oxytocin (OT)-ergic neurons is responsible for ANP release, and it has become clear that activation of neuronal circuitry elicits OT secretion into the circulation, activating atrial OT receptors and ANP release from the heart. Subsequently, we have uncovered the entire functional OT system in the rat and the human heart. An abundance of OT has been observed in the early development of the fetal heart, and the capacity of OT to generate cardiomyocytes (CMs) has been demonstrated in various types of stem cells. OT treatment of mesenchymal stem cells stimulates paracrine factors beneficial for cardioprotection. Cardiovascular actions of OT include: i) lowering blood pressure, ii) negative inotropic and chronotropic effects, iii) parasympathetic neuromodulation, iv) vasodilatation, v) anti-inflammatory activity, vi) antioxidant activity, and vii) metabolic effects. OT actions are mediated by nitric oxide and ANP. The beneficial actions of OT may include the increase in glucose uptake by $\mathrm{CMs}$ and stem cells, reduction in CM hypertrophy, oxidative stress, and mitochondrial protection of several cell types. In experimentally induced myocardial infarction in rats, continuous in vivo OT delivery improves cardiac healing and cardiac work, reduces inflammation, and stimulates angiogenesis. Because OT plays anti-inflammatory and cardioprotective roles and improves vascular and metabolic functions, it demonstrates potential for therapeutic use in various pathologic conditions.
\end{abstract}

Key words: Oxytocin; Natriuretic peptides; Heart; Cardiomyogenesis

\section{Introduction}

The demonstration of bioactivity in pituitary extracts dates back more than a hundred years. In 1895, the vasoconstrictive and hypertensive effects of pituitary extracts were demonstrated by Oliver and Schafer (1). Sir Henry Dale (2) reported in 1906 that intravenous injection of ox posterior pituitary gland extracts into a cat caused the animal's uterus to contract. In further studies, Dale (3) extended his observations of the properties of posterior pituitary extracts and suggested that the substance acting on the smooth muscle of the uterus could also act on the smooth muscle of arteries.

Several groups (4-6) observed a wide variety of physiological effects of neurohypophysis extracts and found conclusive evidence, using fractional precipitation, of the presence of two "active principles", one that produced a rise in blood pressure in dogs and another that stimulated the contraction of uterine muscle in guinea pigs. The two hormones isolated were vasopressin and oxytocin (OT). Another property of OT was reported a few years later by Ott and Scott (7) who found that, in addition to its effect on the uterus, posterior pituitary extracts promoted milk flow in lactating goats by contraction of mammary myoepithelial cells during lactation. Further studies by Paton and Watson in 1912 (8) associated neurohypophysis extracts with blood pressure lowering in birds, the so-called avian depressor effect and von den Velden in 1913 (9) reported inhibition of urine excretion in humans, the antidiuretic effect. Later, it was established that neurohypophysis extracts have both pressor and antidiuretic activity (10). These observations contrasted with other observations associating OT with depressor activity in various species, including humans (4). The discrepancy of some results was solved after the elucidation of OT structure by Du Vigneaud et al. (11) who won the Nobel Prize in 1955. This led to investigations of the biological activity of purified OT. Interestingly,

Correspondence: J. Gutkowska, Laboratory of Cardiovascular Biochemistry, Department of Medicine, Faculty of Medicine, University of Montreal, CHUM Research Centre, 3850 St. Urbain Street, Masson Pavilion, Montreal, Quebec H2W 1T8, Canada. E-mail: jolanta.gutkowska@umontreal.ca

Received July 15, 2013. Accepted November 4, 2013. First published online March 18, 2014. 
Du Vigneaud's research (12) on OT was stimulated by investigations of disulfide groups in the structure of insulin. Remarkably, new evidence associates OT with regulation of obesity and diabetes (13), conditions attributed to insulin resistance and insulin deficiency.

\section{Discovery of the OT system in the heart}

OT is largely synthesized in the supraoptic and paraventricular nuclei of the hypothalamus, with direct OT projections to the dorsal brain stem, a crucial region for cardiovascular regulation (14). In fact, lowered OT expression in the hypothalamus was reported in spontaneously hypertensive rats (15), and a decrease in OT mRNA was correlated with development of hypertension in those animals (16). The background for discovery of OT in the cardiovascular system was created by experiments on atrial natriuretic peptide (ANP) released into the circulation during experimental blood volume expansion (BVE).

The existence of natriuretic peptide was demonstrated in 1981 by de Bold et al. (17) who showed that the heart is the site of the synthesis of a potent diuretic and natriuretic hormone. Immersion in water most probably increases venous return to the heart and dilates the atria, which is followed by increased release of ANP and diuresis. Later studies showed the presence of ANP in other organs including the brain.

Initial experiments demonstrated that ANP inhibits sodium chloride and water intake, since injection of ANP into the third ventricle $(3 \mathrm{~V})$ caused a reduction in dehydration-induced drinking and also the drinking of salt solution by salt-depleted rats (18). This indicated the role of brain ANP neurons in producing natriuresis following stimulation of the anterioventral $3 \mathrm{~V}$ region. The introduction of carbachol in this region caused natriuresis accompanied by a strong increase in plasma ANP concentration and accumulation of the peptide in the medial basal hypothalamus, neurohypophysis, and anterior pituitary gland (19). This suggested that the natriuresis that resulted was brought about, at least in part, by the release of ANP from the brain.

A proposed alternative mechanism was that neural control of electrolyte secretion might be mediated by hypothalamic hormones from the neurohypophysis responsible for ANP release from the heart and subsequent diuresis. The experiments were performed in rats with BVE, the most effective stimuli of ANP efflux. Hypophysectomy and posterior lobectomy completely inhibited the ANP responses to BVE, indicating that a factor originating in the posterior hypophysis is responsible for ANP release (20) and revealing that diuresis and natriuresis, as well as the release of ANP, do not occur in neurohypophysectomized animals. This indicated that a posterior pituitary hormone is responsible for ANP release and, subsequently, diuresis and natriuresis. Further studies showed the role of OT in ANP release. Injection (ip or iv) of OT into rats not only increased sodium excretion but concomitantly elevated plasma ANP $(21,22)$. Thus, it became clear that, during BVE, activation of the neuronal circuitry elicits OT secretion into the circulation, where it reaches the atria and activates atrial OT receptors (OTR) and ANP release from the heart. OT releases $A N P$, in the absence of a central regulatory influence, from isolated atria and during heart perfusion. Therefore, the intracardiac OT stimulating ANP release may be at least in part responsible for the control of cardiovascular homeostasis $(23,24)$.

\section{OT in the cardiovascular system}

Oxytocin action and signaling are mediated by OTRs, which are present in both the heart and large vessels (2426). OTRs have been cloned and sequenced and have been found in many other tissues as well. OTRs are members of a subclass of G-protein-coupled receptors (27), and OTRs transduce signaling via $G \lambda q$ subunits to activate phospholipase $C \beta$ and mitogen-activated protein kinase in uterine cells. The size of OTRs in rat heart appears to be identical to those in the uterus and other organs (24). The presence of OTRs in rat and human hearts was detected by reverse transcription-polymerase chain reaction and by in situ hybridization and autoradiography of atrial and ventricular sections, and was confirmed by competitive binding assay $(24,28)$. A specific OT transcript has been detected in all heart chambers by amplification of rat cDNA by polymerase chain reaction. OTR mRNA content in the heart is about 10 times lower than in the uterus. Immunocytochemical localization of OTR shows the most prominent staining in postnatal cardiomyocytes (CMs) and declines with age to low levels in the adult heart. OTR downregulation was confirmed at the protein level by Western blot analysis. Interestingly, the cardiac OT/OTR system in the fetal heart was upregulated by retinoic acid, a well-recognized major cardiomyogen (29).

The functionality of heart OTRs was demonstrated by the ability of OT to release ANP from isolated perfused rat heart (25) as well as from cardiomyocytes in culture (Figure 1). The presence of an OT antagonist in heart perfusion medium decreased not only OT-stimulated ANP release, but also basal release, indicating that the heart is a site of OT synthesis and supports the hypothesis that these effects could be physiologically relevant.

The highest OT concentration, as measured by radioimmunoassay, was found in the right atrium and was comparable with OT content in the hypothalamus (25); the lowest levels in the heart were found in the ventricles. Amplified fragments of OT genes from the rat heart were identical in size to those in the uterus. Depending on the coupling to distinct G-proteins, cell type, and their location on cellular membranes, OTRs stimulate different second messengers, inducing various physiological effects (30). The signal elicited upon OT 

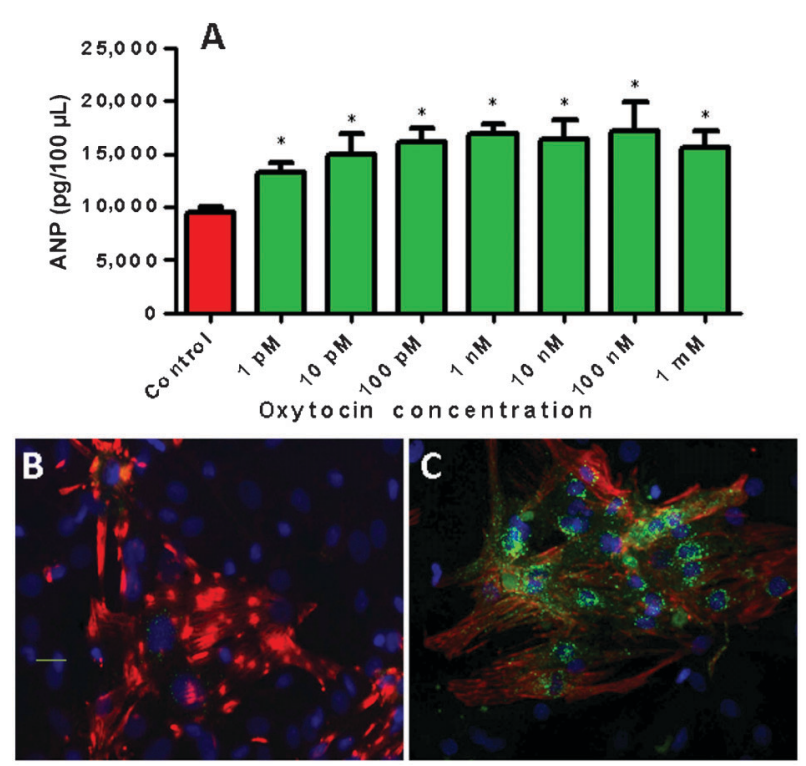

Figure 1. Newborn rat cardiomyocyte culture treated with oxytocin release atrial natriuretic peptide (ANP) to the medium and accumulate ANP in the perinuclear region of the cells. $A$, Radioimmunoassay of ANP from cultures treated with different oxytocin concentrations for $24 \mathrm{~h}$. ${ }^{*} \mathrm{P}<0.05$, compared to control (one-way ANOVA). B, Control cardiomyocyte culture stained with specific marker, troponin $\mathrm{T}$ (red) and nuclear Dapi stain (blue). $C$, Cardiomyocytes treated for $24 \mathrm{~h}$ with $10 \mathrm{pM}$ oxytocin expressed green fluorescence specific for ANP.

binding to its receptor stimulates phospholipase $C \beta$, resulting in inositol-3-phosphate (IP3) and diacylglycerol (DAG) generation. IP3 stimulates $\mathrm{Ca}^{2+}$ release from intracellular stores, and DAG activates protein kinase $\mathrm{C}$, which signals via pro-survival extracellular regulated kinases 1 and 2 (ERK1/2), and other downstream targets. As demonstrated in Figure 2, intracellular $\mathrm{Ca}^{2+}$ mobilization induced by OT action has many effects, including ANP release from CMs (24). Incubation of cells with physiological levels of OT has been shown to protect against oxidative stress and to reduce $\mathrm{H}_{2} \mathrm{O}_{2}$-stimulated NADPH-dependent superoxide activity in vascular cells, monocytes, and macrophages (31). It has also been shown that OT promotes the migration of human dermal endothelial cells (ECs), breast-derived ECs, and human umbilical vein ECs (32). The pro-migratory effect of OT requires OTR activation of the phosphatidylinositol-3kinase (PI3K)/Akt/endothelial nitric oxide (NO) synthase (eNOS) pathway (32). Moreover, OT increases proliferation of mesenchymal cells and alters gene expression of endothelial markers, adhesion molecules, and matrix metalloproteinases, contributing to improved cell motility and growth (33). We have demonstrated that PI3K is involved in OT-stimulated glucose uptake in CMs (34). Furthermore, the results supported the involvement of the calcium-calmodulin kinase kinase (Ca-CAMKK) and 5'
AMP-activated protein kinase (AMPK) pathways, because the respective inhibitors of these enzymes, STO-609 and compound $\mathrm{C}$, blocked stimulated glucose uptake in CMs (34). Correspondingly, in a rabbit model of myocardial infarction (MI), OT induced cardioprotective gene products such as phosphorylated forms of Akt (i.e., protein kinase $B$ ), signal transducer and activator of transcription 3 (STAT3), ERK, matrix metalloproteinase (MMP)-1, and eNOS (35). In the rat heart, an angiogenic and antiapototic OT effect was indicated by vascular endothelial growth factor (VEGF) and B-cell lymphoma (Bcl)-2 protein upregulation in association with increased $\mathrm{CD} 31^{+}$microvessels $(36,37)$.

\section{OT as cardiomyogenic factor}

CM differentiation in early cardiac development is evidenced by the appearance of spontaneous and rhythmic beating, positive staining for cardiac $\alpha$-actin, and significant expression of mRNAs encoding cardiacspecific markers including zinc-finger GATA-4 and Nkx2.5 transcription factors, cardiac $\beta$-myosin heavy chain, and ANP. Observation of the highest activation of the heart OT system in fetal and newborn heart, at the stage of intense hyperplasia (29), suggested the role of OT in the heart as a growth and development or maturation factor. We tested the hypothesis that OT may play a role in cell differentiation. Indeed, initial experiments using mouse embryonic carcinoma P19 cells, a standard stem cell model for studying $\mathrm{CM}$ differentiation, demonstrated that OT induced the formation of functional CMs (38). Since this first study showing that OT induces cardiac differentiation, several reports confirmed OT-stimulated cardiomyogenesis in several lines of embryonic stem cells including somatic stem cells (Sca-1), isolated from adult mouse and rat hearts $(39,40)$, and cardiac stem cell progenitors identified by side population analysis. Therefore, OT has been established as a naturally occurring cardiomorphogen.

In the cardiovascular system, OTR is associated with ANP-cGMP and NO-cGMP systems. Accumulating evidence indicates that $\mathrm{NO}$ is essential for cell differentiation. Inhibition of the NO pathway reduces the number of beating cell colonies as well as transcripts of $N k x 2.5$, $M E F 2 c$, and genes of contractile proteins.

Less pronounced is the inhibition of GATA-4 and ANP genes. These findings show that OT-mediated signaling is physiologically relevant in the formation of new CMs.

\section{Cardioprotective action of OT}

Elucidation of the cellular effects of conditioning and protection from death has revealed a key role for certain key signaling pathways in cardioprotection, and these same pathways have been shown to be stimulated by OTR signaling in cardiac cells. 


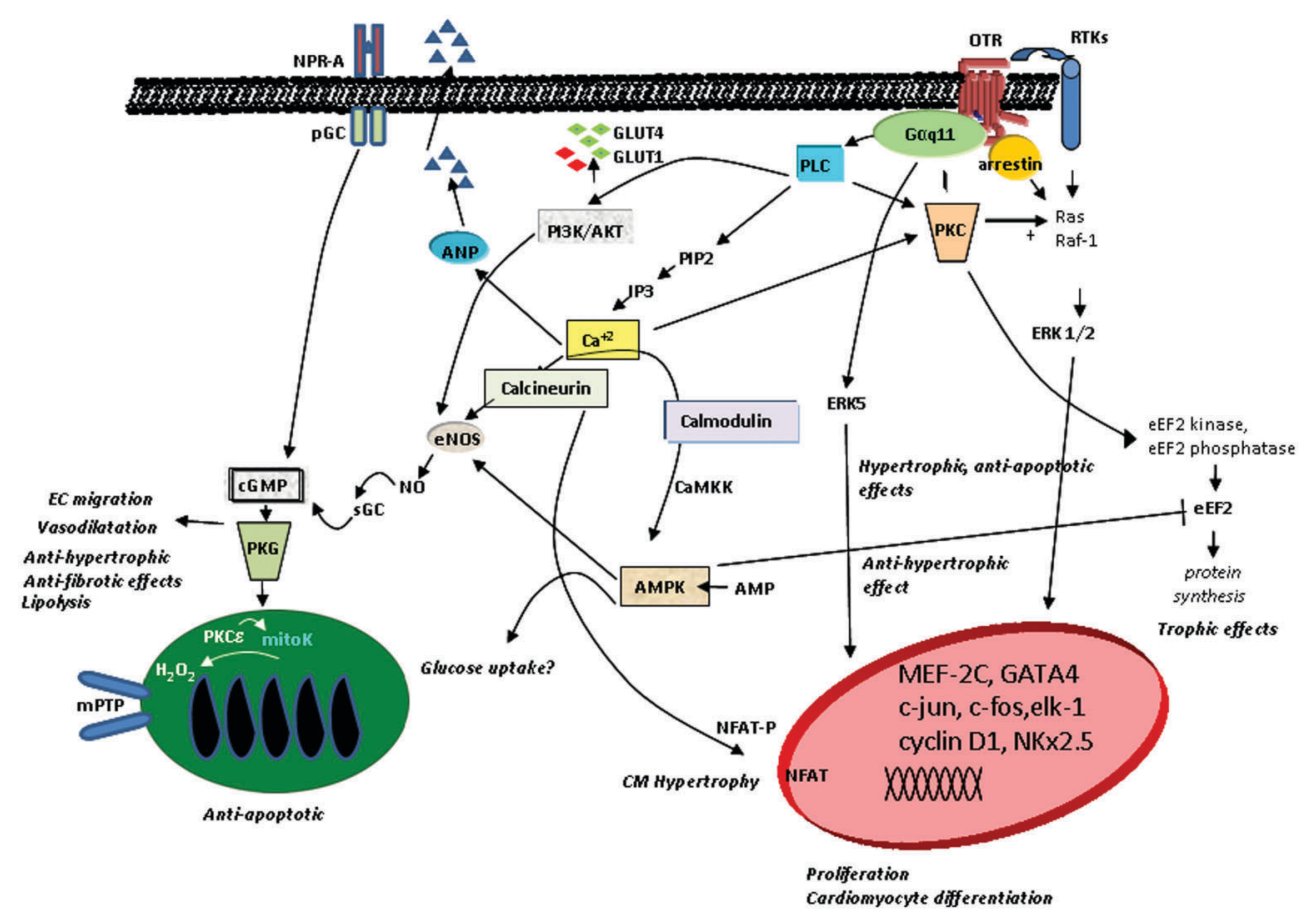

Figure 2. Schematic diagram of potential signaling pathways of OTR in cells of the cardiovascular system (modified from Ref. 73). AMPK: AMP-activated protein kinase; ANP: atrial natriuretic peptide; CaMKK: $\mathrm{Ca}^{2+}$ calmodulin-dependent protein kinase; cGMP: cyclic guanosine monophosphate; CMs: cardiomyocytes; EC: endothelial cells; eEF2: eukaryotic translation elongation factor 2; eNOS: endothelial nitric oxide synthase; ERK: extracellular signal-regulated kinase; GLUT: glucose transporter type; IP3: inositol triphosphate; mitoK: mitochondrial ATP-sensitive potassium channel; mPTP: mitochondrial permeability transition pore; NFAT: nuclear factor of activated T-cells; NO: nitric oxide; NPR-A: natriuretic peptide receptor A; OTR: oxytocin receptor; pGC: particulate guanylyl cyclase; PIP2: phosphatidylinositol 4,5-bisphosphate; PI3K: phosphatidyl-3 kinase; PKC: protein kinase C; PKG: protein kinase G; PLC: phospholipase C; RTKs: receptor tyrosine kinases; sGC: soluble guanylyl cyclase.

\section{OT and OTR}

The expression of OT and its receptor was strongly induced both in the heart and hypothalamus of ovariectomized and sham-operated rats following exercise training, indicating a possible involvement of OT in the cardioprotective effects of exercise (41). In contrast, OTR was downregulated by $40-50 \%$ in the injured left ventricle of mice (42) and rats (36) following MI. The lowering of OTR expression points to the possibility that myocardial injury is accelerated by a deficit of OTR in the heart. We have also observed that OTR downregulation following $\mathrm{MI}$ could be reversed by administration of OT $\left(25-125 \mathrm{ng} \cdot \mathrm{kg}^{-1} \cdot \mathrm{h}^{-1}, \mathrm{sc}\right)$ before the onset of ischemia and during 1 week of reperfusion in a rat model of $\mathrm{Ml}$ (36). Interestingly, the experiments of Alizadeh et al. (43) in isolated, perfused hearts demonstrated that the protective effects of ischemic preconditioning (IPC) were eliminated by administration of an antagonist specific to OTR at the start of IPC, suggesting a possible role for endogenous OT in cardiac ischemic preconditioning. OT also influences injured cardiac function via a central mechanism. Experiments by Wsol et al. (44) demonstrated that icv administration of an OT antagonist significantly enhanced the pressor and tachycardic responses to stress only in shamoperated rats, whereas OT significantly attenuated both responses in infarcted but not in sham-operated rats. Further studies revealed links between social behavior, OT, and autonomic cardiovascular control, which raises the possibility that OT may be part of the mechanism through which social behavior affects cardiovascular health. Socially isolated $\mathrm{ApoE}^{--}$mice treated with OT displayed significantly less atherosclerosis in the thoracic aorta than saline-treated controls (45). Furthermore, electrophysiological studies demonstrated that intranasal OT administration to healthy university-age (20-25 years old) participants produced significant increases in both sympathetic and parasympathetic autonomic cardiac control, and the effects of OT on cardiac autonomic control were significantly associated with loneliness ratings (46).

\section{ANP}

OT stimulates the release of ANP, a known cardioprotective hormone, from isolated, perfused rat heart by 
an OTR-mediated mechanism $(23,24)$. ANP is an established cardioprotective agent; it inhibits the release of renin, inhibits aldosterone synthesis, inhibits sympathetic nerve activity, ameliorates endothelial function, and decreases fibrosis, inflammation, and apoptosis in myocytes that are associated with left ventricle (LV) remodeling (47). ANP has been reported to accelerate NO generation, which mediates late preconditioning. Furthermore, ANP activates reperfusion injury salvage kinase, which has been shown to mediate ischemic preconditioning and postconditioning. In several studies with a reperfusion model in vivo, ANP showed inhibition of the occurrence of reperfusion arrhythmia, preservation of ATP content in the ischemic myocardium, and inhibition of neutrophil-induced endothelial cytotoxity (48).

\section{NO}

OT was also shown to have transient negative inotropic and chronotropic effects on perfused isolated dog right atria in a mechanism independent of ANP release and mediated by NO production and acetylcholine release at cardiac parasympathetic postganglionic neurons (49). Exogenous OT administration has direct negative chronotropic effects (50). Slowing of the heart rate leads to a decrease in myocardial consumption of oxygen and nutrients, and an increase in subendocardial blood flow per beat that may improve regional contractile function (50). Moreover, Ondrejcakova et al. (50) showed that, in isolated rat hearts, a 25 -min perfusion with OT preceding an ischemic insult reduced infarct size by $66 \%$ compared with control hearts. They observed that the elimination of a negative chronotropic effect of OT through electrical stimulation reduced its cardioprotective action. We have already demonstrated that OT treatment of infarcted rats induced eNOS production, normalized ANP mRNA expression in the scar area, and had proproliferative, anti-apoptotic, and anti-fibrotic effects on injured hearts (36). Corresponding results were reported by Kobayashi et al. (35), who demonstrated in a rabbit model of $\mathrm{Ml}$, that daily OT treatments $(10 \mathrm{mg} / \mathrm{kg}, \mathrm{sc})$ immediately following reperfusion significantly reduced infarct size, had pro-angiogenic and anti-fibrotic effects, and increased the activation of pro-survival kinases Akt, ERK1/2, and STAT3, as well as eNOS. Anti-apoptotic Bcl2 was upregulated in the ischemic myocardium following OT treatment, indicating potential anti-apoptotic effects. Interestingly, Akt, ERK, eNOS, and STAT3 have all been previously shown to be mediators of cardiac pre- and post-conditioning (51). Likewise, we demonstrated that OT increases glucose uptake in CMs via the PI3K/Akt/ eNOS pathway (23). Ca-CAMKK-AMPK pathways were also stimulated in OT-activated CMs. The activation of AMPK in the heart following ischemia and reperfusion is recognized as cardioprotective, because AMPK limits apoptosis and suppresses cardiac pathological hypertrophy (52).

\section{Mitochondria and oxidative stress}

We have reported that OT treatment of CMs potentiates the glucose uptake effect of 2,4-dinitrophenol, an uncoupler of oxidative phosphorylation targeting mitochondria (34). Recent research by Alizadeh et al. (43) on isolated, perfused heart showed that the infarct size reduction in the anesthetized rat heart induced by a pretreatment with OT $25 \mathrm{~min}$ prior to ischemia was abrogated by a selective mitochondrial $\mathrm{K}_{\mathrm{ATP}}$ (mitoK $\mathrm{K}_{\mathrm{ATP}}$ ) channel blocker and mitochondrial permeability transition pore (MPTP) opener, suggesting that the cardioprotective effect of OT is caused by mitoK $K_{\text {ATP }}$ channel activation and mPTP blockade. This mechanism has been proposed as the major end-effector of cardioprotective ischemic preand post-conditioning (53). In a study by Das and Sarkar (54), the infarct size-reducing and anti-arrhythmic effects of OT were achieved via selective activation of OTR, $\mathrm{CM}$ mitoK $_{\text {ATP }}$ channels, and NO. The NO contribution suggests the role of CGMP and protein kinase $G$ (PKG) in OT effects on mitochondria. Indeed, PKG inhibits the opening of MPTP through the prolongation of intracellular acidosis, resulting in $\mathrm{Ca}^{2+}$ normalization and prevention of hypercontracture (51).

In ischemic conditions, dysfunction in mitochondrial respiration may increase the formation of reactive oxygen species (ROS), and NADPH oxidase generates ROS in the cytosol of cells subjected to ischemic insult (55). New evidence shows that OT protects against ROS. It was demonstrated in cultured human vascular cells that OT decreases NADPH-dependent superoxide activity via a mechanism involving OTR (31). Similarly, in mesenchymal cells (MSC) treated with OT, increased phosphorylated Akt colocalized with mitochondria, modulated mitochondrial oxidative phosphorylation, and reduced mitochondrial apoptosis (33). The functional analysis of OT-stimulated MSC demonstrated increased cellular proliferation, glucose uptake, cell protection against cytotoxic and apoptotic effects of hypoxia and serum deprivation, and cellular migration. OT improved the paracrine potential of $\mathrm{MSC}$, as demonstrated by increased expression of genes with angiogenic, antiapoptotic, and cardiac anti-remodeling functions and by protection against apoptosis of CMs in coculture (33).

\section{Anti-inflammatory action of OT}

A large body of evidence suggests a regulatory role of OT during immune and inflammatory responses in animal models. OT is synthesized by thymic epithelial cells from different species (56), and each of the major $T$ cell subsets $\left(\mathrm{CD}^{+}{ }^{+}, \mathrm{CD}^{+}\right.$, and gamma delta $\left.{ }^{+}\right)$express OTR (57). The binding of OT to OTR on pre-T cells induces a rapid phosphorylation of focal adhesion-related kinases (58). This could play a major role in the promotion of "immunological synapses" between immature T lymphocytes and antigen-presenting cells, as observed in studies where OTR is expressed in mouse macrophages. 
Moreover, OT affects NO and cytokine production by sepsis-sensitized macrophages (59). Indeed, OT displays anti-inflammatory effects, abolishes the sepsis-induced increase in tumor necrosis factor (TNF)- $\alpha$, and protects against multiple organ damage (60-62). OT-deficient mice exhibit increased stress responses associated with a significant hyperactivation of the hypothalamic-pituitaryadrenal (HPA) axis (63). It has also been reported that OT was found to decrease interleukin (IL)- 6 secretion from macrophages and endothelial cells in a dose-dependent manner, and to attenuate superoxide production in aortic endothelial and smooth muscle cells, monocytes, and macrophages (31).

OT has an anti-inflammatory pathway in atherosclerosis. In vivo chronic OT infusion in Apo-E knockout mice attenuated aortic atherosclerosis and inhibited the secretion of the pro-inflammatory cytokine IL-6 in visceral adipose tissue (45). OT infusion attenuated thoracic aortic atherosclerosis and plasma $\mathrm{C}$-reactive protein (CRP), and may affect inflammatory cytokine expression in adipose tissue in an animal model of dyslipidemia and atherosclerosis, the Watanabe heritable hyperlipidemic rabbit (31). The fact that OT influences both macrophages and adipose tissue, which are not specific to the cardiovascular system, suggests that peripheral OT may have widespread effects on inflammation and disease in other tissues.

$\mathrm{Ml}$ is recognized as a definitive factor for amplification of an excessive and inappropriate inflammatory response (64). There is evidence that OT modulates the inflammation associated with Ml. We have shown that treatment with OT reduced the expression of pro-inflammatory cytokines (TNF- $\alpha$, IL-1 $\beta$, and IL-6) produced by MI back to the levels seen in sham-operated rats; OT also reduced immune cell infiltration including $\mathrm{T}$ lymphocytes, macrophages, and especially neutrophils $(36,65)$. During myocardial ischemia, myocardial TNF- $\alpha$ concentration is rapidly increased and contributes to the development of contractile dysfunction (66). IL-1 $\beta$ and TNF- $\alpha$ reduce ATP production, probably due to the induction of oxidative stress, and thereby myocardial oxygen consumption (67). OT treatment can compensate ATP shortages by stimulating enhanced glucose uptake in CMs (34). Our data also suggest that improvement of cardiac contractile function in response to OT treatment is associated with reduced TNF- $\alpha$ expression in the injured myocardium (36). Furthermore, OT infusion has been shown to stimulate transforming growth factor (TGF)- $\beta$ expression in injured heart tissue (36), pointing to improvement of LV function (68) as well as beneficial effects such as reduced apoptosis and increased cell proliferation (69). Enhanced TGF- $\beta$ can activate CM differentiation from cardiac stem cells (70). OT can also stimulate anti-inflammatory IL-10 mRNA in LV scars (36), and because the mRNA from the infarct zone largely derives from nonmuscle cells invading the site of injury, it is possible that the changes to cytokine
mRNA in the infarct are due to the effects on the inflammatory cells in the region.

\section{OT extended forms}

OT precursor, synthesized in hypothalamic nuclei during post-translational processing, is enzymatically cleaved to yield neurophysin and an extended form OT with three C-terminal amino acids, i.e., OT-Gly-Lys-Arg (or OT-GKR), which is further cleaved by various convertases and amidated to a nine amino acid active peptide OT and two intermediate forms, OT-Gly-Lys and OT-Gly. Recently these extended forms attracted attention, because it was discovered that, in autistic children, although plasma OT was decreased in comparison to normal subjects, the extended forms were increased. The deficit in processing of the extended forms in patients with autism might be implicated in the development of this syndrome (71). We have found an abundant expression of these intermediate forms in the developing heart and investigated the possible implication of these forms in cardiac differentiation of embryonic stem cells. Indeed, OT-GKR has potent OTR-mediated cardiomyogenic activity (72), and to understand better these mechanisms of OT-GKR, an embryonic stem cell line overexpressing this elongated form of OT was generated. Increased spontaneous beating of these cells was observed, and this was accompanied by elevated expression of GATA-4 and myosin light chain (MLC)-2v, indicating induction of embryonic stem cell cardiomyogenesis by OT-GKR. Furthermore, there is evidence that OT-GKR modifies cardiac differentiation toward a ventricular sublineage. OT-GKR increases glucose uptake in isolated neonatal and adult CMs and progenitor cells expressing ATPbinding cassette efflux transporter G2, under physiological conditions and during metabolic stress such as hypoxia, indicating the role of OT in maintenance of cardiac function and cell survival (34). Furthermore, mesenchymal cells transfected with OT-GKR or preconditioned with OT are resistant to apoptosis and express endothelial markers (33). These results are evidence of the bioactivity of the longest intermediate OT precursor OT-GKR in both normal physiological and pathological conditions.

\section{Summary}

The results presented here update our previous analyses of the functional OT system in rat heart and vasculature (73-75). New findings support the concept that local OT production in the heart is physiologically relevant. It is conceivable that ANP released through the activation of OTR slows the heart by inducing a negative chronotropic effect. Early studies also established that OT and ANP act in concert to control body fluid and cardiovascular homeostasis. OT involvement in cardiac 
glucose uptake, inhibition of inflammation, and effects on mitochondria are consistent with the role of OT in cardioprotection. In pathological conditions such as cardiac ischemia and diabetes, OT can be used to stimulate production of lost cardiac cells. The advantage of this therapy is supported by the fact that OT is endogenously produced in the organism, and does not

\section{References}

1. Oliver G, Schafer EA. On the physiological action of extracts of pituitary body and certain other glandular organs: preliminary communication. J Physiol 1895; 18: 277-279.

2. Dale HH. On some physiological actions of ergot. J Physiol 1906; 34: 163-206.

3. Dale $\mathrm{HH}$. The action of extracts of the pituitary body. Biochem J 1909; 4: 427-447.

4. Woodbury AR, Volpitto PP, Hamilton WF. Blood pressure studies of the effects of pituitary preparations on the human. Am J Physiol 1940; 129: 500.

5. Woodbury RA, Hamilton WF, Volpitto PP, Abreu BE, Harper HT. Cardiac and blood pressure effects of pitocin (oxytocin) in man. J Pharmacol 1944; 81: 95-100.

6. Nakano J, Fisher RD. Studies on the cardiovascular effects of synthetic oxytocin. J Pharmacol Exp Ther 1963; 142: 206214.

7. Ott I, Scott JC. The action of infundibulin upon the mammary secretion. Proc Soc Exp Biol Med 1910; 8: 4849, doi: 10.3181/00379727-8-27.

8. Paton DN, Watson A. The actions of pituitrin, adrenalin and barium on the circulation of the bird. J Physiol 1912; 44: 413-424.

9. von den Velden R. [Die Nierenwirkung von Hypophysenextrakten beim Menschen]. Klin Wochschr 1913; 50: 2083-2086.

10. Van Dyke HB. The regulation of water excretion by the neurohypophysis. Bull N Y Acad Med 1953; 29: 24-33.

11. Du Vigneaud V, Ressler $C$, Trippett $S$. The sequence of amino acids in oxytocin, with a proposal for the structure of oxytocin. J Biol Chem 1953; 205: 949-957.

12. Du Vigneaud V. Trail of sulfur research: from insulin to oxytocin. Science 1956; 123: 967-974, doi: 10.1126/ science.123.3205.967.

13. Zhang $\mathrm{H}, \mathrm{Wu} \mathrm{C}$, Chen $\mathrm{Q}$, Chen $\mathrm{X}, \mathrm{Xu} \mathrm{Z}, \mathrm{Wu} \mathrm{J}$, et al. Treatment of obesity and diabetes using oxytocin or analogs in patients and mouse models. PLoS One 2013; 8: e61477, doi: $10.1371 /$ journal.pone.0061477.

14. Sofroniew MV, Weindl A, Schrell U, Wetzstein R. Immunohistochemistry of vasopressin, oxytocin and neurophysin in the hypothalamus and extrahypothalamic regions of the human and primate brain. Acta Histochem Suppl 1981; 24: 79-95.

15. Gaida W, Lang RE, Kraft K, Unger T, Ganten D. Altered neuropeptide concentrations in spontaneously hypertensive rats: cause or consequence? Clin Sci 1985; 68: 35-43.

16. Van Tol HH, van den Buuse $M$, de Jong W, Burbach JP. Vasopressin and oxytocin gene expression in the supraoptic and paraventricular nucleus of the spontaneously hypertensive rat (SHR) during development of hypertension. Brain Res 1988; 464: 303-311. have significant side effects. Moreover, it is now possible to transplant autologous stem cells after previous stimulation with OT inducers, as in the case of a heart infarct. Alternatively, direct treatment with OT molecules could promote cardiomyogenesis in situ and regeneration of a damaged heart.

17. de Bold AJ, Borenstein HB, Veress AT, Sonnenberg H. A rapid and potent natriuretic response to intravenous injection of atrial myocardial extract in rats. Life Sci 1981; 28: 8994, doi: 10.1016/0024-3205(81)90370-2.

18. Gutkowska J, Antunes-Rodrigues J, McCann SM. Atrial natriuretic peptide in brain and pituitary gland. Physiol Rev 1997; 77: 465-515.

19. Baldissera S, Menani JW, dos Santos LF, Favaretto AL, Gutkowska J, Turrin MQ, et al. Role of the hypothalamus in the control of atrial natriuretic peptide release. Proc Natl Acad Sci U S A 1989; 86: 9621-9625, doi: 10.1073/ pnas.86.23.9621.

20. Antunes-Rodrigues J, Ramalho MJ, Reis LC, Menani JV, Turrin MQ, Gutkowska J, et al. Lesions of the hypothalamus and pituitary inhibit volume-expansion-induced release of atrial natriuretic peptide. Proc Natl Acad Sci U S A 1991; 88: 2956-2960, doi: 10.1073/pnas.88.7.2956.

21. Haanwinckel MA, Elias LK, Favaretto AL, Gutkowska J, McCann SM, Antunes-Rodrigues J. Oxytocin mediates atrial natriuretic peptide release and natriuresis after volume expansion in the rat. Proc Natl Acad Sci U S A 1995; 92: 7902-7906, doi: 10.1073/pnas.92.17.7902.

22. Soares TJ, Coimbra TM, Martins AR, Pereira AG, Carnio EC, Branco LG, et al. Atrial natriuretic peptide and oxytocin induce natriuresis by release of cGMP. Proc Natl Acad Sci U S A 1999; 96: 278-283, doi: 10.1073/pnas.96.1.278.

23. Favaretto AL, Ballejo GO, Albuquerque-Araujo WI, Gutkowska J, Antunes-Rodrigues J, McCann SM. Oxytocin releases atrial natriuretic peptide from rat atria in vitro that exerts negative inotropic and chronotropic action. Peptides 1997; 18: 1377-1381, doi: 10.1016/S01969781(97)00209-X.

24. Gutkowska J, Jankowski M, Lambert C, Mukaddam-Daher $\mathrm{S}$, Zingg $\mathrm{HH}$, McCann SM. Oxytocin releases atrial natriuretic peptide by combining with oxytocin receptors in the heart. Proc Natl Acad Sci U S A 1997; 94: 11704-11709, doi: 10.1073/pnas.94.21.11704.

25. Jankowski M, Hajjar F, Kawas SA, Mukaddam-Daher S, Hoffman G, McCann SM, et al. Rat heart: a site of oxytocin production and action. Proc Natl Acad Sci U S A 1998; 95 14558-14563, doi: 10.1073/pnas.95.24.14558.

26. Jankowski M, Wang D, Hajjar F, Mukaddam-Daher S, McCann SM, Gutkowska J. Oxytocin and its receptors are synthesized in the rat vasculature. Proc Natl Acad Sci U S A 2000; 97: 6207-6211, doi: 10.1073/pnas.110137497.

27. Adan RA, van Leeuwen FW, Sonnemans MA, Hoffman G, Verbalis JG, Burbach JP. The rat oxytocin receptor. cDNA cloning and immunocytochemical localization in brain, pituitary, mammary gland and uterus. Adv Exp Med Biol 1995; 395: 345-346. 
28. Cicutti NJ, Smyth CE, Rosaeg OP, Wilkinson M. Oxytocin receptor binding in rat and human heart. Can $J$ Cardiol 1999; 15: 1267-1273.

29. Jankowski M, Danalache B, Wang D, Bhat P, Hajjar F, Marcinkiewicz M, et al. Oxytocin in cardiac ontogeny. Proc Natl Acad Sci U S A 2004; 101: 13074-13079, doi: 10.1073/ pnas. 0405324101.

30. Zingg HH, Laporte SA. The oxytocin receptor. Trends Endocrinol Metab 2003; 14: 222-227, doi: 10.1016/S10432760(03)00080-8.

31. Szeto A, Nation DA, Mendez AJ, Dominguez-Bendala J, Brooks LG, Schneiderman N, et al. Oxytocin attenuates NADPH-dependent superoxide activity and IL-6 secretion in macrophages and vascular cells. Am J Physiol Endocrinol Metab 2008; 295: E1495-E1501, doi: 10.1152/ajpendo. 90718.2008.

32. Cattaneo MG, Lucci G, Vicentini LM. Oxytocin stimulates in vitro angiogenesis via a Pyk-2/Src-dependent mechanism. Exp Cell Res 2009; 315: 3210-3219, doi: 10.1016/ j.yexcr.2009.06.022.

33. Noiseux N, Borie M, Desnoyers A, Menaouar A, Stevens LM, Mansour S, et al. Preconditioning of stem cells by oxytocin to improve their therapeutic potential. Endocrinology 2012; 153: 5361-5372, doi: 10.1210/en.2012-1402.

34. Florian M, Jankowski M, Gutkowska J. Oxytocin increases glucose uptake in neonatal rat cardiomyocytes. Endocrinology 2010; 151: 482-491, doi: 10.1210/en.2009-0624.

35. Kobayashi H, Yasuda S, Bao N, Iwasa M, Kawamura I, Yamada $Y$, et al. Postinfarct treatment with oxytocin improves cardiac function and remodeling via activating cell-survival signals and angiogenesis. J Cardiovasc Pharmacol 2009; 54: 510-519, doi: 10.1097/FJC.0b013e $3181 \mathrm{bfac} 02$.

36. Jankowski M, Bissonauth V, Gao L, Gangal M, Wang D, Danalache B, et al. Anti-inflammatory effect of oxytocin in rat myocardial infarction. Basic Res Cardiol 2010; 105: 205218, doi: 10.1007/s00395-009-0076-5.

37. Jankowski M, Wang D, Danalache B, Gangal M, Gutkowska J. Cardiac oxytocin receptor blockade stimulates adverse cardiac remodeling in ovariectomized spontaneously hypertensive rats. Am J Physiol Heart Circ Physiol 2010; 299: H265-H274, doi: 10.1152/ajpheart.00487.2009.

38. Paquin J, Danalache BA, Jankowski M, McCann SM, Gutkowska J. Oxytocin induces differentiation of P19 embryonic stem cells to cardiomyocytes. Proc Natl Acad Sci U S A 2002; 99: 9550-9555, doi: 10.1073/pnas. 152302499.

39. Oyama T, Nagai T, Wada H, Naito AT, Matsuura K, Iwanaga $\mathrm{K}$, et al. Cardiac side population cells have a potential to migrate and differentiate into cardiomyocytes in vitro and in vivo. J Cell Biol 2007; 176: 329-341, doi: $10.1083 / \mathrm{jcb} .200603014$.

40. Matsuura K, Nagai T, Nishigaki N, Oyama T, Nishi J, Wada $\mathrm{H}$, et al. Adult cardiac Sca-1-positive cells differentiate into beating cardiomyocytes. J Biol Chem 2004; 279: 1138411391, doi: 10.1074/jbc.M310822200.

41. Gutkowska J, Paquette A, Wang D, Lavoie JM, Jankowski M. Effect of exercise training on cardiac oxytocin and natriuretic peptide systems in ovariectomized rats. $A m \mathrm{~J}$ Physiol Regul Integr Comp Physiol 2007; 293: R267-R275, doi: 10.1152/ajpregu.00071.2007.
42. Indrambarya $\mathrm{T}$, Boyd $\mathrm{JH}$, Wang $\mathrm{Y}$, McConechy M, Walley KR. Low-dose vasopressin infusion results in increased mortality and cardiac dysfunction following ischemiareperfusion injury in mice. Crit Care 2009; 13: R98, doi: 10.1186/cc7930.

43. Alizadeh AM, Faghihi M, Sadeghipour HR, Mohammadghasemi $F$, Khori $V$. Role of endogenous oxytocin in cardiac ischemic preconditioning. Regul Pept 2011; 167: 8690, doi: 10.1016/j.regpep.2010.11.004.

44. Wsol A, Cudnoch-Jedrzejewska A, Szczepanska-Sadowska E, Kowalewski S, Dobruch J. Central oxytocin modulation of acute stress-induced cardiovascular responses after myocardial infarction in the rat. Stress 2009; 12: 517-525, doi: 10.3109/10253890802687688.

45. Nation DA, Szeto A, Mendez AJ, Brooks LG, Zaias J, Herderick EE, et al. Oxytocin attenuates atherosclerosis and adipose tissue inflammation in socially isolated ApoE-/mice. Psychosom Med 2010; 72: 376-382, doi: 10.1097/ PSY.0b013e3181d74c48.

46. Norman GJ, Cacioppo JT, Morris JS, Malarkey WB, Berntson GG, DeVries AC. Oxytocin increases autonomic cardiac control: moderation by loneliness. Biol Psychol 2011; 86: 174-180, doi: 10.1016/j.biopsycho.2010.11.006.

47. Kasama S, Furuya M, Toyama T, Ichikawa S, Kurabayashi $M$. Effect of atrial natriuretic peptide on left ventricular remodelling in patients with acute myocardial infarction. Eur Heart J 2008; 29: 1485-1494, doi: 10.1093/eurheartj/ ehn206.

48. Ishii H, Amano T, Matsubara T, Murohara T. Pharmacological intervention for prevention of left ventricular remodeling and improving prognosis in myocardial infarction. Circulation 2008; 118: 2710-2718, doi: 10.1161/CIRCU LATIONAHA.107.748772.

49. Mukaddam-Daher S, Yin YL, Roy J, Gutkowska J, Cardinal R. Negative inotropic and chronotropic effects of oxytocin. Hypertension 2001; 38: 292-296, doi: 10.1161/01.HYP.38. 2.292.

50. Ondrejcakova M, Ravingerova T, Bakos J, Pancza D, Jezova D. Oxytocin exerts protective effects on in vitro myocardial injury induced by ischemia and reperfusion. Can J Physiol Pharmacol 2009; 87: 137-142, doi: 10.1139/Y08108.

51. Ovize M, Baxter GF, Di Lisa F, Ferdinandy P, GarciaDorado D, Hausenloy DJ, et al. Postconditioning and protection from reperfusion injury: where do we stand? Position paper from the Working Group of Cellular Biology of the Heart of the European Society of Cardiology. Cardiovasc Res 2010; 87: 406-423, doi: 10.1093/cvr/ cvq129.

52. Beauloye C, Bertrand L, Horman S, Hue L. AMPK activation, a preventive therapeutic target in the transition from cardiac injury to heart failure. Cardiovasc Res 2011; 90: 224-233, doi: 10.1093/cvr/cvr034.

53. Skyschally A, Schulz R, Heusch G. Pathophysiology of myocardial infarction: protection by ischemic pre- and postconditioning. Herz 2008; 33: 88-100, doi: 10.1007/ s00059-008-3101-9.

54. Das B, Sarkar C. Is preconditioning by oxytocin administration mediated by iNOS and/or mitochondrial K(ATP) channel activation in the in vivo anesthetized rabbit heart? Life Sci 2012; 90: 763-769, doi: 10.1016/j.Ifs.2012.03.030. 
55. Tsutsui $\mathrm{H}$, Kinugawa S, Matsushima S. Oxidative stress and heart failure. Am J Physiol Heart Circ Physiol 2011; 301: H2181-H2190, doi: 10.1152/ajpheart.00554.2011.

56. Wiemann M, Ehret G. Subcellular localization of immunoreactive oxytocin within thymic epithelial cells of the male mouse. Cell Tissue Res 1993; 273: 79-87, doi: 10.1007/ BF00304614.

57. Ndiaye K, Poole DH, Pate JL. Expression and regulation of functional oxytocin receptors in bovine T lymphocytes. Biol Reprod 2008; 78: 786-793, doi: 10.1095/biolreprod.107. 065938.

58. Martens H, Kecha O, Charlet-Renard C, Defresne MP, Geenen V. Neurohypophysial peptides stimulate the phosphorylation of pre-T cell focal adhesion kinases. Neuroendocrinology 1998; 67: 282-289, doi: 10.1159/ 000054324

59. Oliveira-Pelegrin GR, Saia RS, Carnio EC, Rocha MJ. Oxytocin affects nitric oxide and cytokine production by sepsis-sensitized macrophages. Neuroimmunomodulation 2013; 20: 65-71, doi: 10.1159/000345044.

60. Detillion CE, Craft TK, Glasper ER, Prendergast BJ, DeVries AC. Social facilitation of wound healing. Psychoneuroendocrinology 2004; 29: 1004-1011, doi: 10. 1016/j.psyneuen.2003.10.003

61. Iseri SO, Sener G, Saglam B, Gedik N, Ercan F, Yegen BC. Oxytocin protects against sepsis-induced multiple organ damage: role of neutrophils. J Surg Res 2005; 126: 73-81, doi: 10.1016/j.jss.2005.01.021.

62. Petersson M, Wiberg U, Lundeberg T, Uvnas-Moberg K. Oxytocin decreases carrageenan induced inflammation in rats. Peptides 2001; 22: 1479-1484, doi: 10.1016/S01969781(01)00469-7.

63. Amico JA, Mantella RC, Vollmer RR, Li X. Anxiety and stress responses in female oxytocin deficient mice. $J$ Neuroendocrinol 2004; 16: 319-324, doi: 10.1111/j.09538194.2004.01161.x.

64. Bodi V, Sanchis J, Nunez J, Mainar L, Minana G, Benet I, et al. Uncontrolled immune response in acute myocardial infarction: unraveling the thread. Am Heart $J$ 2008; 156: 1065-1073, doi: 10.1016/j.ahj.2008.07.008.

65. Al-Amran F, Shahkolahi M. Oxytocin ameliorates the immediate myocardial injury in rat heart transplant through downregulation of neutrophil-dependent myocardial apoptosis. Transplant Proc 2013; 45: 2506-2512, doi: 10. 1016/j.transproceed.2013.03.022.
66. Dorge H, Schulz R, Belosjorow S, Post H, van De Sand A, Konietzka I, et al. Coronary microembolization: the role of TNF-alpha in contractile dysfunction. J Mol Cell Cardiol 2002; 34: 51-62, doi: 10.1006/jmcc.2001.1489.

67. Ebermann L, Piper C, Kuhl U, Klingel K, Schlattner U, Siafarikas N, et al. Impact of myocardial inflammation on cytosolic and mitochondrial creatine kinase activity and expression. Basic Res Cardiol 2009; 104: 247-257, doi: 10.1007/s00395-008-0773-5.

68. Frantz S, Hu K, Adamek A, Wolf J, Sallam A, Maier SK, et al. Transforming growth factor beta inhibition increases mortality and left ventricular dilatation after myocardial infarction. Basic Res Cardiol 2008; 103: 485-492, doi: 10.1007/ s00395-008-0739-7.

69. Frangogiannis NG. The immune system and cardiac repair Pharmacol Res 2008; 58: 88-111, doi: 10.1016/j.phrs. 2008.06.007

70. Abdel-Latif A, Zuba-Surma EK, Case J, Tiwari S, Hunt G, Ranjan S, et al. TGF-beta1 enhances cardiomyogenic differentiation of skeletal muscle-derived adult primitive cells. Basic Res Cardiol 2008; 103: 514-524, doi: 10.1007/ s00395-008-0729-9.

71. Green L, Fein D, Modahl C, Feinstein C, Waterhouse L, Morris M. Oxytocin and autistic disorder: alterations in peptide forms. Biol Psychiatry 2001; 50: 609-613, doi: 10.1016/S0006-3223(01)01139-8.

72. Gassanov N, Devost D, Danalache B, Noiseux N, Jankowski $\mathrm{M}$, Zingg $\mathrm{HH}$, et al. Functional activity of the carboxyl-terminally extended oxytocin precursor peptide during cardiac differentiation of embryonic stem cells. Stem Cells 2008; 26: 45-54, doi: 10.1634/stemcells.20070289.

73. Gutkowska J, Jankowski M. Oxytocin revisited: its role in cardiovascular regulation. J Neuroendocrinol 2012; 24: 599608, doi: 10.1111/j.1365-2826.2011.02235.x.

74. Gutkowska J, Jankowski M, Mukaddam-Daher S, McCann SM. Oxytocin is a cardiovascular hormone. Braz J Med Biol Res 2000; 33: 625-633, doi: 10.1590/S0100-879X2000 000600003.

75. McCann SM, Antunes-Rodrigues J, Jankowski M, Gutkowska J. Oxytocin, vasopressin and atrial natriuretic peptide control body fluid homeostasis by action on their receptors in brain, cardiovascular system and kidney. Prog Brain Res 2002; 139: 309-328, doi: 10.1016/S00796123(02)39027-7. 